\title{
EARTHQUAKE-RESISTANT DESIGN
}

\author{
Proper design and construction can prevent \\ loss of life and minimize economic loss
}

\author{
by Donald E. Hudson
}

Every year there are about 1,000,000 true earthquakes occurring in the earth. Most of these are so small that they can be detected only by sensitive instruments, but about 100,000 of them could be felt to some degree by human beings located near the origin. Fortunately, only about 100 are of a size sufficient to cause severe damage, and most of them occur far from any man-made structures. As an average there are each year perhaps a dozen or so earthquakes that cause significant damage somewhere in the world. These dozen are enough to represent a heavy economic loss and a continuing hazard to life and limb in many areas of the world. According to a recent UNESCO report, earthquakes between 1926 and 1950 resulted in 350,000 human deaths and an economic loss estimated at $\$ 10$ billion.

Even though the number of earthquakes is not expected to increase significantly, the severity of the problem is sure to grow, because the world is

Donald E. Hudson, professor of mechanical engineering and applied mechanics, with one of the strongmotion accelerographs that will be installed in Cattech's new Millikan Library.

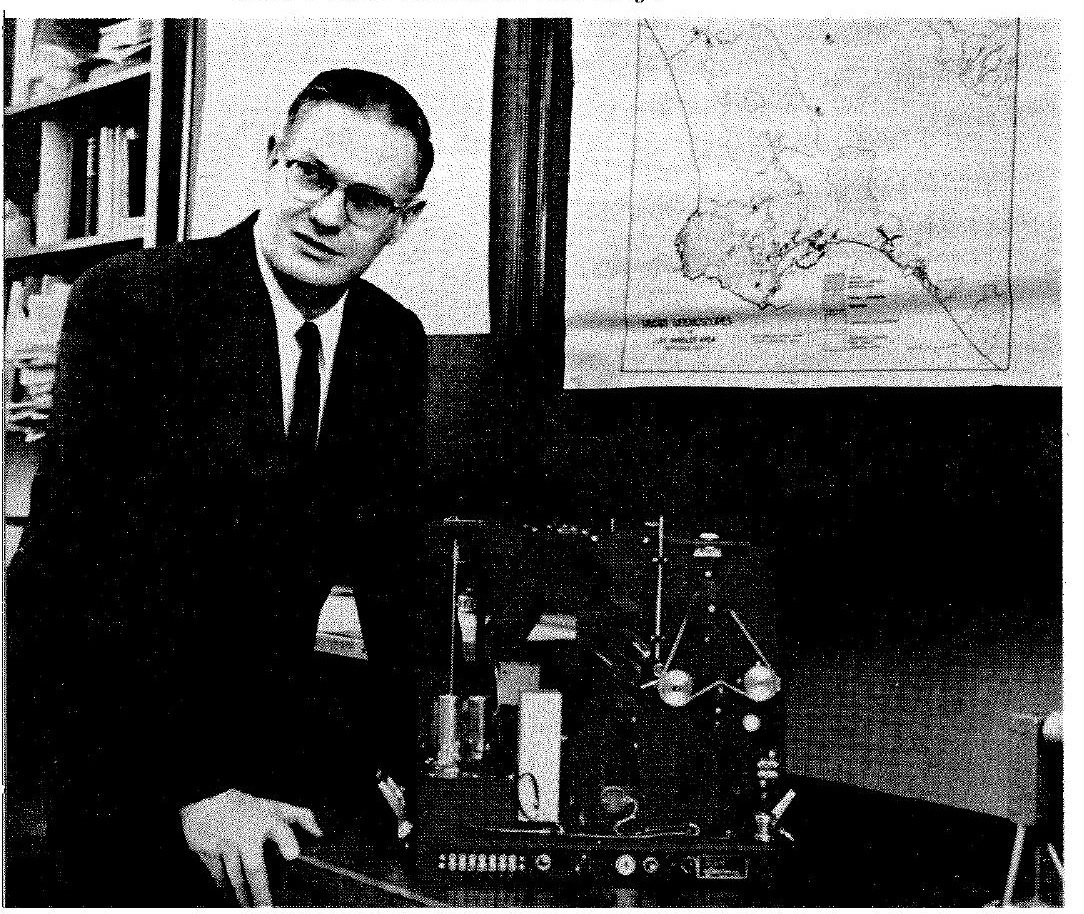

rapidly filling up with people and structures. For example, had the Alaska earthquake of 1964 occurred a few years earlier, there would have been much less damage, because there would have been few structures in the area.

Studies based primarily on the work of Caltech seismologists Charles Richter and the late Beno Gutenberg and reported in their book Seismicity of the Earth have shown that the distribution of earthquakes over the earth is far from uniform. About 80 percent of the world's earthquakes occur in a relatively narrow belt circling the Pacific Ocean. The most seismic parts of the United States are the Pacific Coast states, which form a segment of this basic circum-Pacific belt. It cannot be assumed, however, that destructive earthquakes will not occur in other parts of the country. Very large earthquakes occurred in the central Mississippi Valley (1811-1812) and in Charleston (1886), and several sharp shocks have been felt in the Boston area during the past 100 years.

Earthquakes are commonly described by their magnitude, measured on the Richter scale, but many of the most destructive in terms of property and lives were seismologically "moderate or small." A brief survey of recent well-known earthquakes shows that the Alaska earthquake was perhaps not quite as large as the 1960 Chile earthquake, and both were probably exceeded by the Assam [India] earthquake of 1950. The San Francisco earthquake of 1906 is definitely down the scale a little, and the Kern County earthquake of 1952, the most recent one to cause appreciable damage in Los Angeles, was of an intermediate size. Of equal interest is the low end of the scale; Agadir [Morocco] and Skopje [Yugoslavia], which did immense damage and killed thousands of people, were relatively small earthquakes that happened to occur close to densely populated areas with many very weak structures.

Engineering and Science 
Similarly, the destructive Santa Barbara and Long Beach earthquakes, which made a deep impression on the southern California consciousness of the earthquake hazard, were relatively small. The number of small earthquakes far exceeds that of large earthquakes; there are on the average about 12 shocks of magnitude 6 each year, but only one of magnitude 8.

A magnitude 8.5 earthquake would cause structural damage over an area of about 100,000 square miles (the area of southern California); the Long Beach earthquake (magnitude 6.3) caused damage over some 300 square miles. In light of the greater number of smaller earthquakes, however, it can be concluded that there is almost as much total damage from smaller earthquakes as from the larger. The bigger ones nevertheless present more of a problem, since damage over a very wide area complicates relief and rescue work and intensifies the economic problems of recovery and reconstruction.

Considering past data on the numbers of earthquakes of various sizes occurring in California and the areas of damage associated with each, one can arrive at the number of years that should elapse on the average between destructive ground motions at any particular point. It is found for any point in California that the expected frequency of experiencing ground motion equal to or greater than that in Long Beach during the 1933 earthquake is about once per 70 years. Smaller magnitudes of shaking will be felt more often, but the 70-year figure is a good one to keep in mind in relation to the expected life of structures.

One cannot "run away from earthquakes" in California by locating structures far from known faults; there are too many faults distributed throughout the state. A common opinion now is that perhaps the whole of California should be considered to have approximately the same earthquake risk.

\section{Effects of earthquakes on structures}

Structural damage caused by earthquakes falls into two broad classes: that caused primarily by a disruption of the foundation, and that caused by shaking of the ground. The dangers of foundation disruption were clearly shown in the Alaska earthquake, where landslides caused great damage. In one instance a hospital, which withstood the shaking of the earthquake as it had been designed to do, narrowly escaped destruction when a landslide came within a few feet of it. Although the hospital site has obvious scars that are evidence of former landslides, those warnings were ignored, and a water supply tank was erected right on the edge of a

February 1966 previous slide. This whole situation illustrates one type of precaution that should certainly be taken in locating buildings. No amount of skill in structural design could withstand an undermining of the foundation by such landslides. Other areas in Anchorage were not as fortunate, and a large fraction of the damage there was the result of houses being engulfed in massive slides.

A second kind of foundation disturbance was shown in Niigata [Japan] where whole buildings tilted as though they were rolling in a heavy sea. One large multi-story apartment house rotated through an angle of 80 degrees in foundation soil that was "liquefied" by the earthquake shaking. Even though this concrete building finished up on its side, little structural damage occurred.

The type of damage that is most susceptible to analysis occurs when buildings on firm ground are shaken by an earthquake. Before-and-after photographs of a multi-story office building in Agadir show what happened during the 1960 earthquake. Although the building disintegrated because of the shaking of the solid ground, telephone poles remained firmly planted in the ground.

\section{Measurement of destructive ground motion}

It might be expected that information about the shaking of the ground during destructive earthquakes would be obtained from the instruments in seismological laboratories. However, those instruments are for the most part sensitive devices designed to record distant earthquakes giving rise to extremely small ground motions. If a strong earthquake should occur near the station, the instruments would read off-scale, or might even, as in Tokyo in 1923, be thrown off their bases onto the

Even if a structure is well built, a poorly chosen site can lead to disaster in an earthquake, as almost happened at this hospital in Anchorage. Note the scars of old landslides to the right of the latest break.

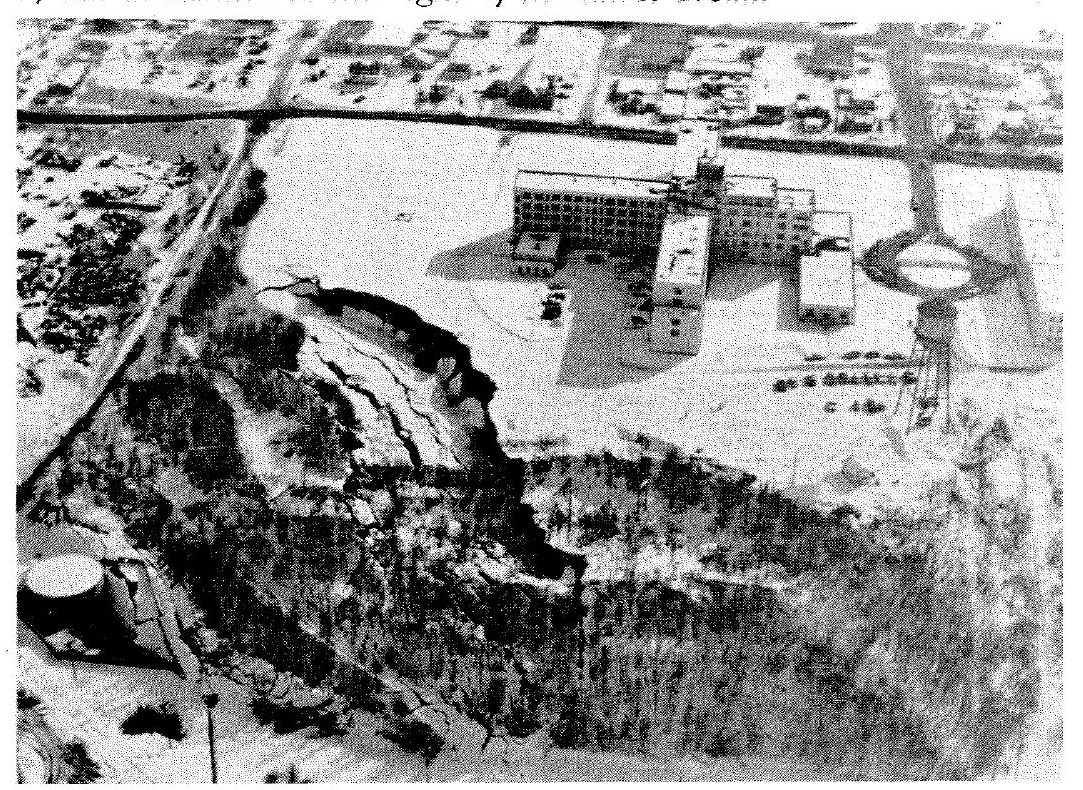



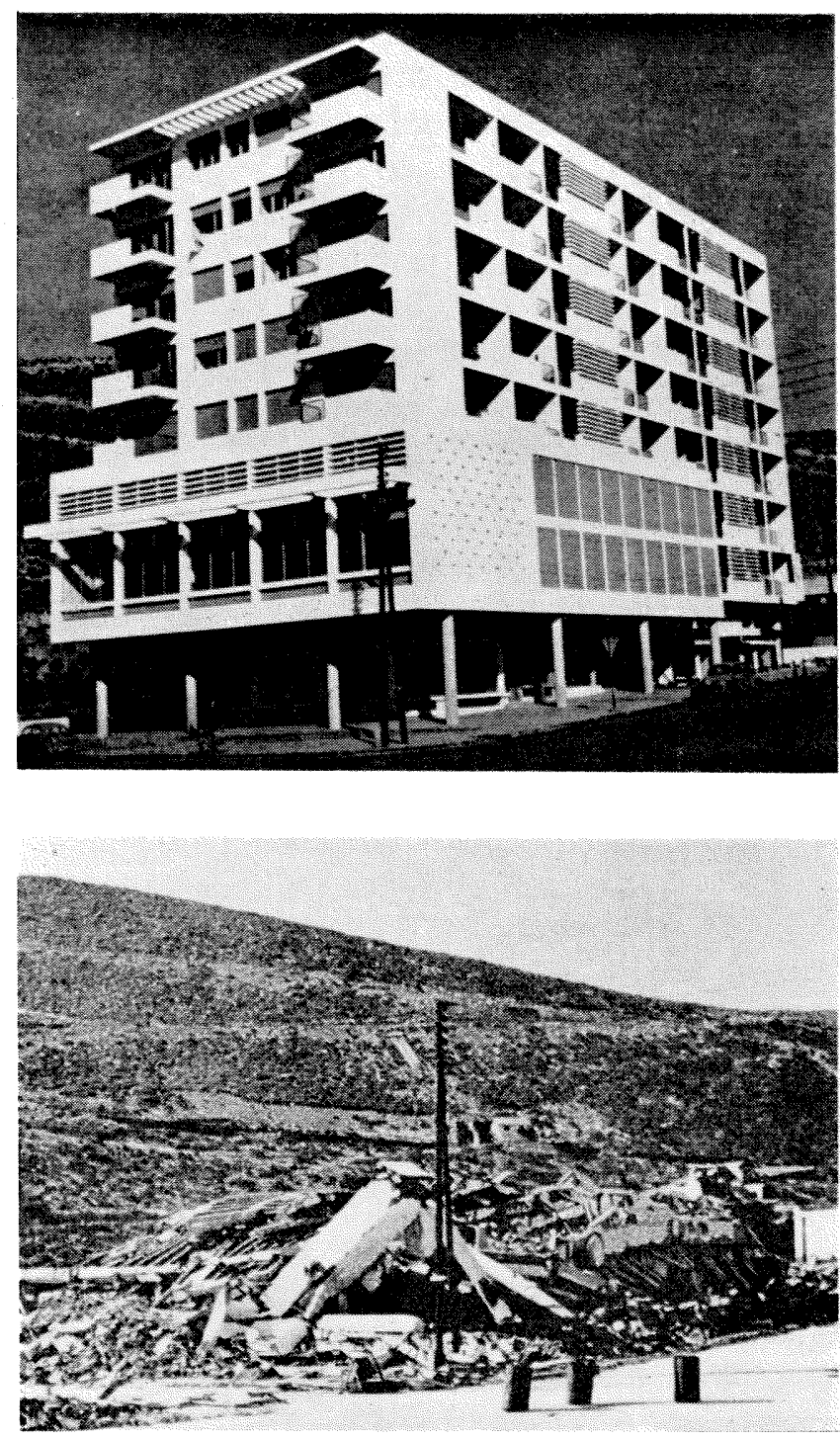

This building in Agadir, Morocco, collapsed during an earthquake, although the ground remained firm. Another "structure," the telephone pole, was unharmed.

floor. Earthquake engineers must thus design and install their own rugged instruments specifically for the purpose of recording big earthquakes.

\section{Recording strong ground motion}

A special strong-motion accelerograph has been designed for recording three components of the ground acceleration versus time during strong earthquakes. Because the recording paper must move fairly rapidly to permit the analysis required by the engineer, it is not feasible to run the paper continuously as in seismological instruments. The instrument must be triggered by the earthquake which is to be recorded. This is done by a starting pendulum, which at the beginning of the ground motion makes an electric contact to start the photographic paper and turn on the recording light.

One of the biggest deficiencies of the present en- gineering studies of earthquakes is the lack of a sufficient number of such instruments. In order to give a usable record, the device must be located within 20 to 30 miles of a large earthquake. The area to be covered is immense, and thousands of instruments are needed where only hundreds exist at present.

Because of this lack of instruments, for only one recent, destructive earthquake-Niigata-has a record of the strong ground motion occurring in the region of damage been obtained. Of course this lack of basic data hampers studies of what happened, since in examining ruins one is often not sure whether the damage was caused by a heavy ground motion or by an especially weak structure.

The U.S. Coast and Geodetic Survey maintains a network of recording instruments, which includes 15 accelerographs in Alaska installed since 1964. Unfortunately, there were no instruments in Alaska to measure the destructive ground motions of the 1964 earthquake. Because of the limited area of coverage of each instrument and the small probability of occurrence of a strong earthquake sufficiently near any particular instrument, such networks must be operated for many years to accumulate useful data. There is a concentration of instruments in San Francisco and Los Angeles where there are many important structures on various foundation conditions. In addition, several buildings in San Francisco and Los Angeles have instruments in upper-story positions to record the behavior of the building during earthquakes. Such simultaneous measurements of ground motion and building response make it possible to consider a strong earthquake as a full-scale, dynamic test of the structure, from which significant dynamic properties can be computed.

In spite of the small number of instruments, a number of excellent records of strong ground motion have been obtained. One, the El Centro 1940 earthquake record, has become in a sense a standard earthquake for all workers in the field. A technical paper on the subject from any seismic country (such as Japan, Russia, Chile) will probably refer to it.

The El Centro earthquake had a maximum horizontal acceleration of about one-third the acceleration of gravity. George Housner, Caltech professor of civil engineering and applied mechanics, has made a special study of the maximum horizontal acceleration that might be expected close to a fault on firm alluvium during an earthquake, and he has concluded that it is of the order of one-half the acceleration of gravity. There are reasons for supposing that the properties of the earth's crust are such

continued on page 24

Engineering and Science 
that more destructive shaking is unlikely or even impossible. Similarly, the maximum time duration of strong shaking is of the order of 45 seconds, although the shaking may be felt for a longer period.

\section{Designing for Safety}

A typical building, in the absence of earthquakes or wind, supports its own weight and contents as vertical loads. The effect of an earthquake is mainly to apply horizontal loads to the building. As a first approximation, these horizontal forces are proportional to the weights of the floors, and also to the ground acceleration. A secondary effect is a modification of the vertical loads because of vertical accelerations, but this is not usually as important a factor as the horizontal force.

To illustrate the potentially destructive nature of a horizontal force, consider a simple structure formed by placing a beam on top of two columns without connections. Such a structure might adequately support a vertical load, but could easily be toppled by a horizontal load. A simple way to cure this difficulty would be to connect the members together so that when a horizontal force acts, the structure perhaps bends, but does not collapse. This illustrates one of the most important principles of earthquake-resistant design-that the structure should be firmly connected together so that it acts as a unit. This may seem to be such an obvious consideration that it hardly needs to be mentioned. Nevertheless, failure to remember it is the basic cause of much earthquake damage, as was illustrated by a number of instances of complete collapse during the Alaska earthquake.

A second simple type of difficulty may exist when two different buildings are close together. Being different, the two buildings are likely to vibrate in a different way during an earthquake, one zigging while the other zags. The consequent pounding of the two buildings can do severe local damage, and this has often been noted in past earthquakes. One cure, of course, is to provide a sufficient clearance between the structures to prevent contact.

A rather more complicated difficulty can be illustrated by an L-shaped asymmetrical building, where one part of the building is much stiffer than the other. Differences in the way in which the two sections vibrate may set up a damaging condition at the juncture of the two sections. This does not mean that asymmetrical buildings should not be built, but special provisions should be made to strengthen them at critical sections.

Much earthquake damage can be traced to a relatively few basic design errors such as those just mentioned. The cure for such difficulties is more widespread dissemination of information among architects and engineers.

Among the steps taken to ensure safe structures, perhaps the most important is the establishment of building codes or regulations containing directions for earthquake-resistant design and construction. A properly formulated building code embodying current knowledge in the field, backed up by legally enforced inspection and control, can go a long way toward assuring public safety during earthquakes. Such building codes are not as common or as comprehensive as is often supposed.

The most widely used building code in the west is the Uniform Building Code of the Pacific Coast Building Officials Conference. This code, which covers all aspects of construction, is issued in a standard form that can be legally adopted by various municipalities and government agencies. At present some 650 such agencies have officially adopted it. However, the existence of the standard code does not mean that all cities have officially adopted it, or that, if adopted, it is effectively enforced. The universal experience of all countries has been that an earthquake code itself without a vigorous and continuous inspection and enforcement policy is of little use. In any given region, therefore, the question to ask is not whether an earthquake code exists, but whether or not there is an active local group backing it.

The first effective earthquake-resistant building code in California appeared in 1927 in the first published edition of the Uniform Building Code. Since then the code has been revised every few years to keep up with the increasing knowledge. The Long Beach earthquake of 1933 was the real breakthrough in the development of regulation and control. As a direct consequence of the great damage to school buildings in the Long Beach earthquake, the Legislature of the State of California, through the Field Act, assigned to the State Division of Architecture the authority and responsibility, under the police power of the state, to approve or reject plans and specifications and to supervise construction of all public school buildings. The State Division of Architecture has carried this assignment out with great effectiveness, and all California school buildings built since 1933 have been

continued on page 26

Engineering and Science 
designed and constructed under careful supervision with respect to earthquake forces.

For many years both San Francisco and Los Angeles operated under building codes different from each other and from the Uniform Building Code. In 1960 a special Seismology Committee of the Structural Engineers Association of California developed a standard earthquake code which now has almost universal acceptance, so that Los Angeles, San Francisco, and the Uniform Building Code all have virtually the same earthquake provisions.

It is not to be supposed that an earthquake code is a comprehensive treatise on earthquake-resistant design. The complete earthquake section of the Uniform Building Code runs to only a dozen or so pages; it is only a guide for a trained and experienced designer. Such building codes must always presuppose the existence of a high-level professional activity in the area.

\section{Earthquake engineering research at Caltech}

For many years basic problems of the behavior of structures subjected to earthquake forces have been studied at Caltech. One type of problem which has been solved involves a simple one-story structure consisting of a mass mounted on horizontally flexible columns. It is supposed that the ground has the acceleration of a measured past earthquake, and a calculation of the maximum deflection of the building with respect to the ground is made. This maximum deflection is plotted against the ratio of mass to stiffness, so that for any given structure an idea of the deformation caused by the earthquake can be worked out. Whether or not the calculated deformation is dangerous for the structure must of course be further examined. Analyses have been made for all of the past strong earthquakes for which good ground acceleration records are available. By a comparison of the results of such calculations, it has been possible to express certain average properties of past strong earthquakes in a form that is useful for design purposes.

A second research field in which the Caltech group has been active is that of the dynamic testing of full-scale structures. Because of the difficulty and expense of making tests of large structures, there are many gaps in the basic knowledge of the dynamic characteristics of such things as multi-story buildings, bridges, and dams. To learn more about such problems, a special system of vibration genera- tors has been developed at Caltech under the sponsorship of the California State Division of Architecture. A test program was carried out in cooperation with the Los Angeles Department of Water and Power in which a set of four vibration generators was mounted at the crest of an earthfilled dam. With this system, a sinusoidally varying horizontal force of 20,000-pound amplitude can be produced over a range of accurately determined frequencies. By measuring the motion of the dam at various frequencies, one can calculate the dynamic physical properties of the dam in the asconstructed condition. Similar tests have been made in several multi-story buildings and in various special structures, such as large rocket test stands, and a considerable clarification of the dynamic properties of structures has resulted.

Current design philosophy does not attempt to avoid all damage, but does intend to prevent the kind of complete collapse that would lead to injury or loss of life. Once this has been accomplished, the designer hopes to balance repair costs against the increased initial building costs that would have been necessary to prevent damage completely. This is clearly a statistical problem which requires for its satisfactory solution improvements in knowledge of the probability of occurrence of earthquakes in a particular region and of the true dynamic behavior of structures.

If all existing knowledge can be employed and good construction techniques and high-quality materials can be ensured, there is no reason why structures cannot be made safe in the above sense against the most violent earthquakes. The principal danger in the world today comes from the millions of old structures that were built either before present knowledge existed, or under economic conditions that for various reasons did not permit suitable quality construction. Unfortunately, a large fraction of the world's population must live in houses that would inevitably collapse in even a small earthquake. This is a problem that is being investigated by several UNESCO committees, but as yet no satisfactory solution to this immediate practical problem seems to be in sight.

Although there are a number of such pressing practical problems remaining to be solved, it may be said that the basic knowledge of the effects of earthquakes on structures is at present extensive and is steadily advancing. It may thus be expected that, with the proper effort, the world will ultimately be relatively free of serious earthquake hazards. 